\title{
Two-Dimensional and Doppler Echocardiographic Evaluation After Arterial Switch Repair in Infancy for Complete Transposition of the Great Arteries
}

\author{
Monica M. Martin, MD, A. Rebecca Snider, MD, Edward L. Bove, MD, Gerald A. Serwer, MD, \\ Amnon Rosenthal, MD, Jane Peters, and Patricia Pollock
}

\begin{abstract}
The most recent postoperative echocardiographic examinations of all children who underwent arterial switch repair of transposition of the great arteries from August 1985 to December 1987 were reviewed. The patients included 35 children whose age at operation was $12 \pm 16$ days and whose weight was $3.6 \pm 0.4 \mathrm{~kg}$. Thirty-three patients are alive and well; 1 died intraoperatively and 1 died immediately postoperatively. The time of the follow-up echocardiographic examination ranged from 1 day to 2.5 years (mean 9.2 months) with 11 patients examined $>1$ year after surgery. Complete examination of the repair site was possible in all patients. Echocardiographic visualization of distortion of the great arteries at the suture lines was seen in all patients; however, Doppler evidence of hemodynamically significant obstruction at the repair site was uncommon. On Doppler examination in the surviving 33 patients, 16 had no supravalvular pulmonary stenosis and 14 had mild to moderate supravalvular pulmonary stenosis with peak systolic pressure gradients ranging from 16 to $56 \mathrm{~mm} \mathrm{Hg}$ (mean 31). Three patients had severe supravalvular pulmonary stenosis and peak systolic pressure gradients of 66, 74 and $77 \mathrm{~mm} \mathrm{Hg}$ (2 have had reoperation, 1 is awaiting surgery). On Doppler examination, 4 patients had mild supravalvular aortic stenosis with peak systolic gradients ranging from 10 to $29 \mathrm{~mm} \mathrm{Hg}$. Doppler gradients were confirmed in 10 patients who had catheterization $12 \pm 3$ months after surgery. Three patients had mild pulmonary regurgitation by Doppler examination, 5 had mild aortic regurgitation, 4 had mild tricuspid regurgitation and $\mathbf{2}$ had mild mitral regurgitation. In all 33 patients, ventricular dimensions, left ventricular shortening fraction (42 \pm $6 \%$ ) and rate-corrected mean velocity of circumferential fiber shortening ( $1.25 \pm 0.24$ circumference) s) were normal.
\end{abstract}

(Am J Cardiol 1989;63:332-336)
$\mathrm{I}$ $\mathrm{n}$ children with d-transposition of the great arteries, anatomic correction with the arterial switch procedure is rapidly gaining widespread acceptance as the operation of choice. ${ }^{1-11}$ Compared to intraatrial baffle procedures, the arterial switch procedure offers the advantage of reinstating the left ventricle as the systemic pumping chamber. Long-term complications of intraatrial baffle procedures, such as arrhythmias, baffle obstructions and right ventricular failure, are not expected to develop after arterial switch repair. However, the long-term results of arterial switch repair in infancy are unknown and patients who have undergone this procedure require frequent postoperative assessment. Two-dimensional and Doppler echocardiography provide important noninvasive techniques for evaluating the child who has had arterial switch repair in infancy. We describe echocardiographic findings in all children who underwent arterial switch repair at our institution through December 1987.

\section{METHODS}

Patients: The patients were 35 children who had an artcrial switch procedure at our institution from August 1985 to December 1987. Twenty-nine patients were male and 6 were female. The age at operation ranged from 1 day to 10 weeks (mean 12 days). Twenty-four patients were $<7$ days old at the time of surgery, 4 were 8 to 14 days old and 7 were $>14$ days old. The weight at the time of operation ranged from 2.7 to $4.4 \mathrm{~kg}$ (mean 3.6).

The diagnoses of the 35 patients are summarized in Table I. Twenty-five patients had situs solitus, d-loop, dtransposition of the great arteries with intact ventricular septum. One of these patients had left juxtaposition of the right atrial appendage and 1 had a single right coronary artery. Four patients had d-transposition with a membranous ventricular septal defect large enough to require patch closure at the time of the arterial switch procedure. Two patients had Taussig-Bing anomaly.

From the Departments of Pediatrics and Surgery, C.S. Mott Children's Hospital, University of Michigan Medical Center, Ann Arbor, Michigan. Manuscript received June 13, 1988; revised manuscript received October 12, 1988, and accepted October 13.

Address for reprints: A. Rebecca Snider, MD, F1609, C.S. Mott Children's Hospital, University of Michigan Medical Center, Ann Arbor, Michigan 48109 . 


\begin{tabular}{|lc|}
\hline TABLE I Diagnoses of Arterial Switch Patients $(n=35)$ \\
\hline Diagnoses & Pts $(n)$ \\
\hline d-TGA/IVS & 25 \\
d-TGA, memb VSD & 4 \\
Taussig-Bing anomaly & 2 \\
d-TGA, outlet VSD, coarctation repair & 1 \\
DORV, d-TGA, VSD, coarctation & 1 \\
d-TGA, inlet VSD, LSVC to CS & 1 \\
d-TGA, outlet VSD, cleft AMVL & 1 \\
\hline AMVL = anterior mitral valve leafiet; CS = coronary sinus; DORV = double outlet \\
right ventricle; IVS = intact ventricular septum; LSVC $=$ left superior vena cava; memb \\
= membranous; TGA = transposition of the great arteries; VSD = ventricular septal \\
defect.
\end{tabular}

One of these had a previous pulmonary artery band and underwent an arterial switch procedure at age 2 months; the other underwent a total repair at age 3 weeks. One patient with d-transposition of the great arteries, an outlet ventricular septal defect and coarctation of the aorta underwent coarctation repair before the arterial switch operation and 1 patient with double outlet right ventricle, d-transposition of the great arteries and coarctation of the aorta underwent coarctation repair at the time of the arterial switch procedure. One patient with d-transposition, inlet ventricular septal defect, left superior vena cava to the coronary sinus, left juxtaposition of the right atrial appendage and right aortic arch and 1 patient with d-transposition and an outlet ventricular septal defect also underwent patch closure of the ventricular septal defect at the time of surgery. All but 1 patient had preoperative cardiac catheterization and 30 patients had balloon atrial septostomy. Ten patients have had elective postoperative cardiac catheterization.

Operative procedure: The details of the operative procedure have been described previously. ${ }^{11}$ The repair was accomplished using low flow cardiopulmonary bypass at a systemic temperature of $20^{\circ} \mathrm{C}$. In 1 patient, multiple anomalies of the systemic venous return required the repair to be done during a single period of circulatory arrest. Associated atrial and ventricular septal defects were closed first, after which the great vessels were transected. The distal aorta was repositioned posterior to the pulmonary artery bifurcation ${ }^{10}$ except in patients with extreme anterior position of the pulmonary artery. After the proximal pulmonary artery (neoaortic root) was anastomosed to the distal aorta, each coronary artery was excised with a wide button of aortic wall and relocated to the facing sinus of the neoaorta. The defects resulting from coronary excision were closed with pericardium and the repair was completed with the anastomosis of the proximal aorta (neopulmonary artery) to the pulmonary bifurcation.

Echocardiographic evaluation: The postoperative evaluation included M-mode, 2-dimensional and Doppler echocardiographic examinations. All patients received oral chloral hydrate for sedation before the examination. The time interval from the day of operation to the most recent postoperative echocardiographic examination ranged from 1 day (in the patient who died immediately postoperatively) to 2.5 years (mean \pm standard deviation $9.2 \pm 7.7$ months). Fifteen patients had their last echocardiographic examination within 6 months of surgery, 8 were examined between 6 and 12 months after surgery and 11 have been examined $>1$ year after surgery. The patient who died in the operating room had no postoperative echocardiogram. Right and left ventricular dimensions, left ventricular shortening fraction and heart rate-corrected mean velocity of circumferential fiber shortening were measured from the $\mathbf{M}$-mode echocardiogram. ${ }^{12,13}$ Cardiac wall motion and the anatomy of the supravalvular anastomotic areas were assessed with 2-dimensional echocardiography. Two-dimensional range-gated pulsed Doppler echocardiography was used to detect valvular regurgitation and valvular or supravalvular stenosis. Doppler peak gradients were calculated using the simplified Bernoulli equation. ${ }^{14}$

\section{RESULTS}

Surgical results: Thirty-three children are alive, well and asymptomatic. One patient with transposition and an intact ventricular septum died in the operating room and 1 patient with Taussig-Bing anomaly and a previous pulmonary artery band died on the first postoperative day. Autopsy examination in this latter patient showed a kinked right coronary artery. Three patients with d-transposition of the great arteries and intact ventricular septum developed severe supravalvular pulmonary stenosis. Two had reoperation at 2 and 15 months after the arterial switch procedure and 1 is awaiting surgery.

Echocardiographic findings: Complete echocardiographic examinations were obtained in all 34 patients who survived surgery. The patient who died on the first postoperative day had markedly depressed left and right ventricular contractility on the postoperative examination and no other abnormal findings. The remainder of this article includes the echocardiographic findings from the surviving 33 patients.

Right and left ventricular dimensions were within normal limits for body surface area in all 33 patients. The shortening fraction of the left ventricle $(42 \pm 6 \%)$ and mean velocity of circumferential fiber shortening corrected for heart rate $(1.25 \pm 0.24$ circumference $/ \mathrm{s})$ were also normal, suggesting normal left ventricular systolic function. On 2-dimensional echocardiographic examination, right ventricular anterior wall motion and left ventricular posterior wall motion were normal. No areas of akinetic or dyskinetic wall motion were seen.

In all patients, the surgical repair was well visualized on the 2-dimensional echocardiogram from multiple transducer locations. In each patient, an area of anatomic narrowing was imaged in the ascending aorta beginning at the suture line (Figures 1 and 2). This narrowing was caused by a discrepancy in size between the original large pulmonary valve (now the new aortic valve) and the smaller ascending aorta. Although distortion of the newly reconstructed left ventricular outflow tract was seen by 2-dimensional imaging in all patients, only 4 patients had mild supravalvular aortic stenosis by Doppler examination. Their peak systolic pressure gradients ranged from 10 to $29 \mathrm{~mm} \mathrm{Hg}$ (mean 19). 
Distortion of the main pulmonary artery above the pulmonary valve was also visualized in all patients on the 2-dimensional echocardiogram (Figures 3 and 4). This distortion usually consisted of a long segment of narrowing, which included the suture line as well as the large patches over the areas where the coronary arteries and a surrounding "button" of the aortic root were removed. Of the 33 patients, 16 had normal peak velocity $(<1.7 \mathrm{~m} / \mathrm{s})$ in the main pulmonary artery distal to the

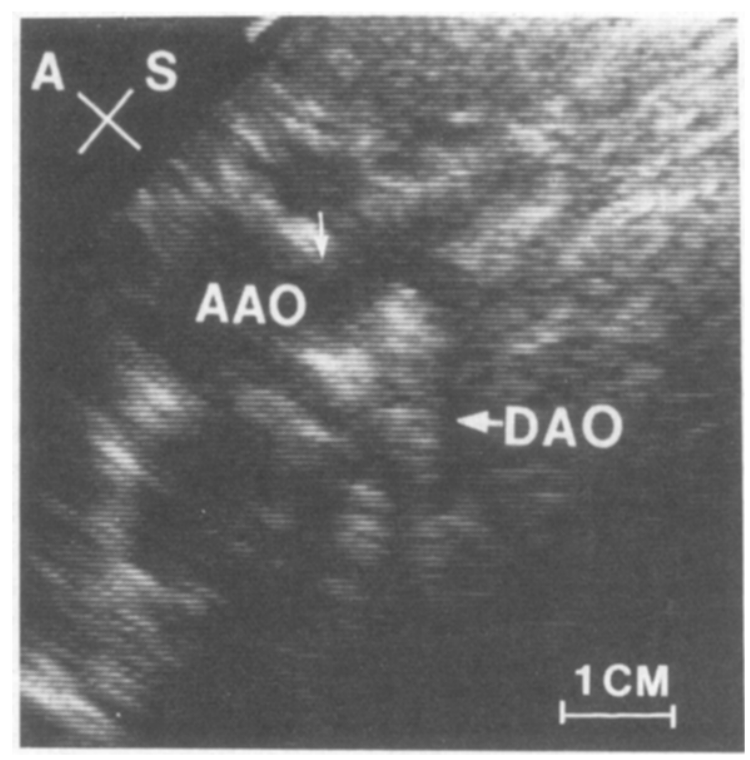

FIGURE 1. Suprasternal long-axis view of the aortic arch from a patient with d-transposition of the great arteries and intact ventricular septum after arterial switch repair. Note the distortion of the ascending aorta (AAO) above the aortic valve (arrow). This represents the area of the suture line where the original large main pulmonary artery was sewn to the smaller ascending aorta. This patient had a 29-mm $\mathrm{Hg}$ peak gradient by Doppler examination in the AAo across the suture line. $A=$ anterior; $\mathrm{DAO}=$ descending aorta; $\mathrm{S}=$ superior.

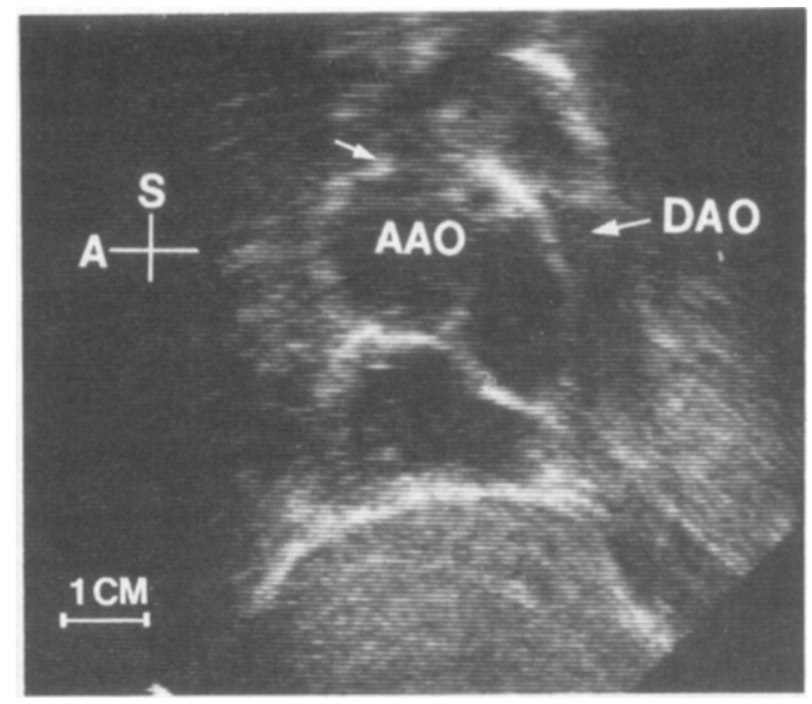

FIGURE 2. Subcostal sagittal view of the aortic arch from the same patient as in Figure 1. The distortion in the ascending aorta (AAo) at the suture line is again evident (arrow). Abbreviations as in Figure 1. repair site. Fourteen patients had mild to moderate supravalvular pulmonary stenosis with Doppler peak systolic pressure gradients ranging from 16 to $56 \mathrm{~mm}$ $\mathrm{Hg}$ (mean 31). Of these 14 patients, 4 had peak gradients of 16 to $20 \mathrm{~mm} \mathrm{Hg}, 8$ had peak gradients of 21 to $50 \mathrm{~mm} \mathrm{Hg}$ and 2 had peak gradients of 53 and $56 \mathrm{~mm}$ Hg. Three patients developed sevcre supravalvular pulmonary stenosis with Doppler peak systolic pressure gradients of 66,74 and $77 \mathrm{~mm} \mathrm{Hg}$. Two of these patients underwent successful repair of supravalvular pulmonary stenosis at 2 and 15 months after the arterial switch procedure and 1 patient is scheduled for reoperation.

Ten patients had cardiac catheterization $12 \pm 3$ months postoperatively. Close agreement was found between catheterization peak to peak gradients and Doppler peak gradients across both outflow tracts (Table II).

Valvular regurgitation was graded as mild (detectable on Doppler examination but without chamber enlargement), moderate (easily detected on Doppler examination with mild chamber enlargement) or severe (easily detected on Doppler examination with marked chamber enlargement, evidence of large diastolic runoff in the descending aorta or main pulmonary artery in the case of aortic or pulmonary regurgitation). Five patients had mild aortic regurgitation, 3 patients had mild pulmonary regurgitation, 4 had mild tricuspid regurgitation and 2 had mild mitral regurgitation. No patient had moderate or severe valvular regurgitation and no

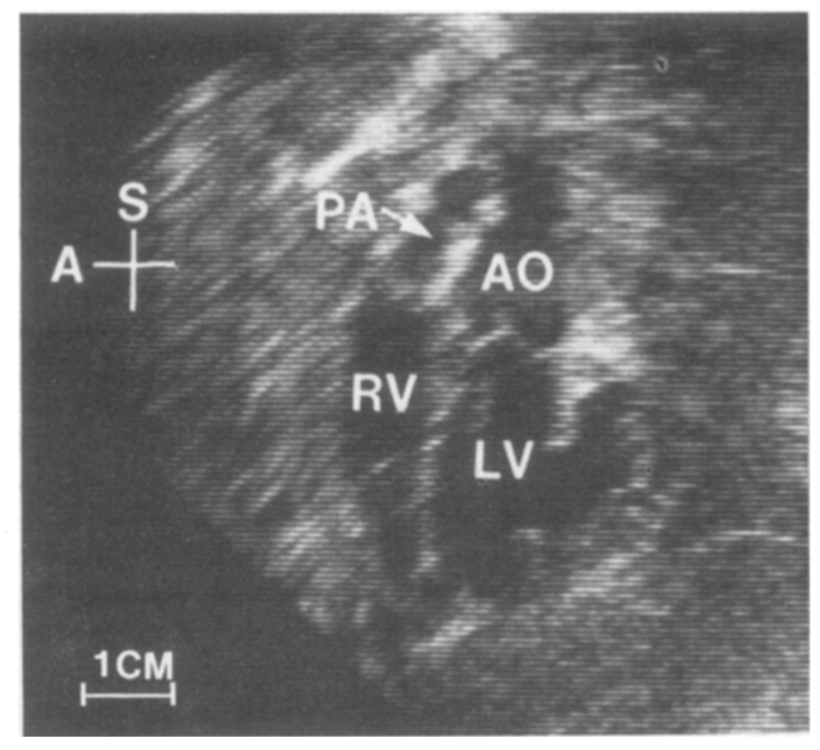

FIGURE 3. Subcostal sagittal view from a patient with dtransposition of the great arteries and intact ventricular septum after arterial switch repair. Note the uniform narrowing of the pulmonary artery (PA) above the pulmonary valve. This area represents the area of the suture line and the area where large patches were placed when the coronary arteries and a surrounding portion of the aortic root were removed. Despite this apparent narrowing by 2-dimensional echocardiography, this patient had ino evidence on Doppler examination and by cardiac catheterization of supravalvular pulmonary stenosis. $A=$ anterior; $A o=$ aorta; $L V=$ left ventricle; $R V=$ right ventricle; $\mathbf{S}=$ superior. 


\begin{tabular}{|c|c|c|c|c|c|c|c|}
\hline \multirow[b]{2}{*}{ Pt } & \multicolumn{2}{|c|}{ Time from Operation to } & \multicolumn{2}{|c|}{ Supra PS Gradient } & \multicolumn{2}{|c|}{ Supra AS Gradient } & \multirow{2}{*}{$\begin{array}{l}E F \\
(\%)\end{array}$} \\
\hline & Echo & Cath & Echo & Cath & Echo & Cath & \\
\hline 1 & 14 & 14 & 77 & 84 & 0 & 0 & - \\
\hline 2 & 11 & 11 & 16 & 11 & 0 & 0 & 79 \\
\hline 3 & 50 & 13 & 25 & 20 & 29 & 0 & 70 \\
\hline 4 & 20 & 18 & 16 & 12 & 0 & 0 & 80 \\
\hline 5 & 9 & 6 & 74 & 44 & 0 & 0 & 68 \\
\hline 6 & 10 & 10 & 0 & 0 & 0 & 0 & 64 \\
\hline 7 & 10 & 10 & 24 & 18 & 0 & 0 & 77 \\
\hline 8 & 13 & 13 & 41 & 27 & 0 & 0 & 72 \\
\hline 9 & 11 & 13 & 66 & 66 & 0 & 0 & - \\
\hline 10 & 15 & 15 & 0 & 0 & 0 & 0 & 64 \\
\hline
\end{tabular}

patient had a change in the amount of valvular regurgitation during the follow-up period.

Three patients who had a bicuspid pulmonary valve preoperatively by 2-dimensional echocardiography now have a bicuspid aortic valve. None of these patients has developed aortic stenosis or regurgitation. In the patients with patch closure of a ventricular septal defect, Doppler detection of left-to-right shunting of blood across the patch in the first few postoperative days was common; however, none has a residual ventricular septal defect on the last postoperative Doppler examination. Also, the patients with coarctation repair have no residual coarctation gradient on their last Doppler examination.

\section{DISCUSSION}

Two-dimensional and Doppler echocardiography are important noninvasive techniques for evaluation of the child after arterial switch repair of transposition of the great arteries. The echocardiographic examination should focus on 3 major areas: detection of newly created structural abnormalities, detection of residual structural abnormalities and evaluation of systolic and diastolic function.

Newly created structural abnormalities: The surgical maneuvering required to perform the arterial switch repair can result in newly created structural abnormalities, the most common of which is supravalvular pulmonary stenosis. Structural distortion of the main pulmonary artery above the new pulmonary valve (old aortic valve) is commonly seen by 2 -dimensional echocardiography. Usually, the narrowing includes the suture line and the large patches over the areas where the coronary arteries and a surrounding portion of the aortic root have been removed.

We have found it difficult to assess the hemodynamic significance of supravalvular pulmonary stenosis on the basis of imaging information alone. Therefore, we rely on a Doppler estimate of the peak systolic pressure gradient across the main pulmonary artery. In our experience, significant obstruction above the pulmonary valve is uncommon, occurring in only 3 of our 33 patients (9\%). Fourteen of 33 patients (44\%) had Doppler peak gradients across the main pulmonary artery of 16 to $56 \mathrm{~mm} \mathrm{Hg}$ indicating mild to moderate supravalvular pulmonary stenosis. Further follow-up examinations are necessary to determine if the mild stenosis detected in these patients will progress to severe obstruction.

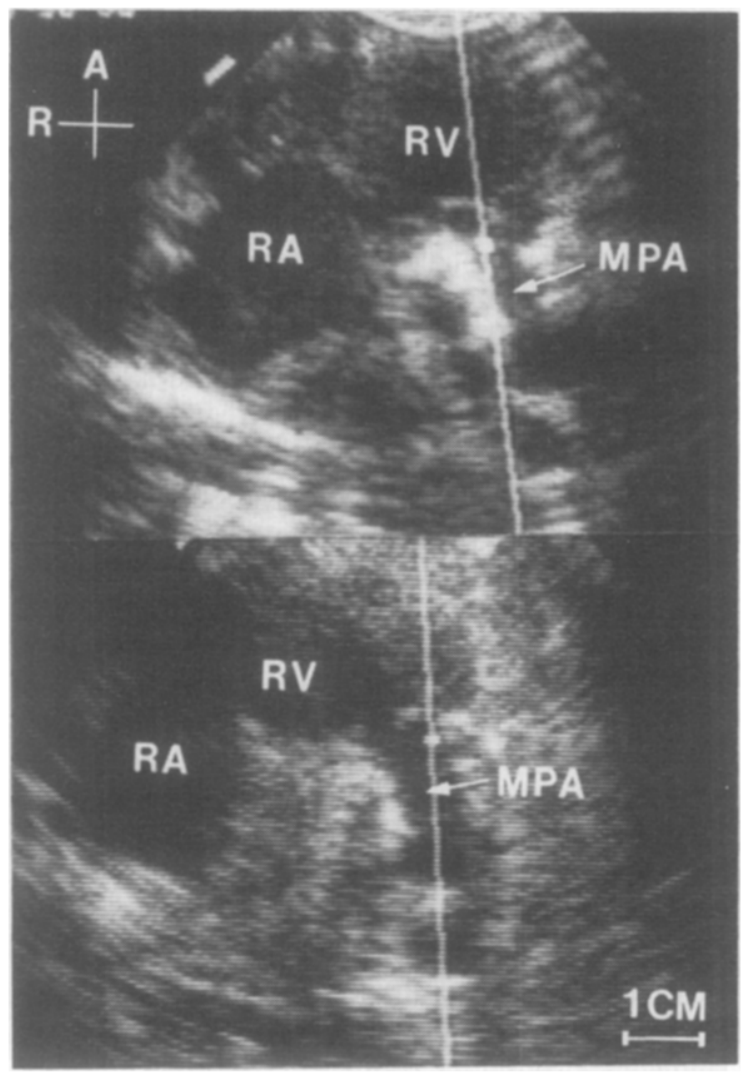

FIGURE 4. Top, parasternal short-axis view from an infant with d-transposition of the great arteries and intact ventricular septum after the arterial switch repair. This infant had a long segment of narrowing in the main pulmonary artery (MPA) above the pulmonary valve. Doppler examination of the MPA distal to the long segment of narrowing (not in the area of the sample volume shown) showed a $77-\mathrm{mm} \mathrm{Hg}$ peak gradient in the MPA. Bottom, parasternal short-axis view of the same patient after repair of supravalvular pulmonary stenosis. The caliber of the MPA has been widened by a patch repair. Dopp. ler examination in the distal MPA showed a normal peak velocity after reoperation. $\mathbf{A}=$ anterior, $\mathbf{R}=$ right, $\mathbf{R A}=$ right atrium, $\mathbf{R V}=$ right ventricle. 
Anatomic distortion of the newly created ascending aorta is seen on the 2-dimensional echocardiographic examination in all patients after the arterial switch procedure. This distortion occurs where the smaller ascending aorta is sewn to the larger main pulmonary artery above the original pulmonary valve (now the patient's aortic valve). Because of the size discrepancy between these 2 structures, the narrowing often appears very severe by 2-dimensional imaging even when Doppler examination shows no evidence of obstruction. Thus, the severity of supravalvular aortic stenosis should not be based on imaging information alone, but rather on a careful estimate of the peak gradient across the ascending aorta using Doppler echocardiography. In our series, significant supravalvular aortic stenosis has not been encountered in any patient after arterial switch repair.

Valvular regurgitation can occur as a new finding after the switch procedure or can take on added significance after surgery. For example, what may appear preoperatively to be normal physiologic pulmonary regurgitation in an infant with transposition can persist postoperatively-now as aortic regurgitation. In the 5 patients we have followed with mild aortic regurgitation, no change in the amount of regurgitation has occurred. Similarly, no change has occurred in the patients with pulmonary, tricuspid or mitral regurgitation.

A small percentage of patients with d-transposition of the great arteries have a bicuspid pulmonary valve. After arterial switch repair, these patients have a newly created abnormality - a bicuspid aortic valve. The 3 patients we have followed with a bicuspid aortic valve have not developed aortic stenosis or regurgitation; however, further follow-up examinations are necessary to determine the fate of the newly created bicuspid aortic valve.

The arterial switch procedure requires the mobilization of small, delicate coronary arteries, thus creating the potential for damage to these vessels, either in the immediate postoperative period or as a late postoperative complication. In our patients, no coronary artery obstruction or kinking was detected; however, the coronary arteries could not be examined completely in all patients and minor amounts of luminal narrowing could have been missed due to limitations in resolution.

Residual structural abnormalitiesi Besides the detection of newly created structural abnormalities, the echocardiographic examination is useful for detecting residual structural abnormalities, such as residual atrial or ventricular shunts or residual coarctation.

Ventricular function: The arterial switch procedure has the theoretical advantage of reinstating the left ventricle as the systemic pumping chamber in children with d-transposition of the great arteries, thus eliminating the long-term complication of right ventricular failure. However, the arterial switch procedure requires the mobilization of small, delicate coronary arteries, thus creating the potential for left ventricular ischemia, either in the immediate postoperative period or as a late postoperative complication. M-mode echocardiographic mea- surements of the left ventricular end-systolic pressuredimension and wall stress-shortening relations, sensitive indexes of contractility, have been normal at varying afterloads in children who have had the arterial switch procedure. ${ }^{15}$ Likewise, peak left ventricular shortening rate measured from the digitized M-mode echocardiogram has becn normal after arterial switch repair. ${ }^{16}$ All of our patients had normal M-mode echocardiographic indexes of left ventricular systolic function and normal right and left ventricular wall motion by 2-dimensional echocardiography at rest. Further noninvasive studies are necessary to assess ventricular function during exercise and to evaluate ventricular diastolic function.

Acknowledgment: The authors wish to thank Drs. Samuel Lacina, Michael Florentine and Antonio Peschicra, whose support and assistance allowed us to obtain the postoperative echocardiographic examinations for many of the patients. We also wish to thank Lyne Merida-Asmus for editorial assistance.

\section{REFERENCES}

1. Jatene AD, Fontes VF, Souza LCB, Neger F, Galantier M, Souza JEMR Anatomic correction of transposition of the great vessels. $J$ Thorac Cardiovasc Surg 1977;72:364-372.

2. Yacoub MH, Bernhard A, Lange PE, Radley Smith R, Keck EW, Heintzen $\mathrm{PH}$. Clinical and hemodynamic results of the two-stage anatomic correction of transposition of the great arteries. Circulation 1980;62(suppl I):I-190-I-196. 3. Huugen TJ, Colan SD, Norwoud WI, Sanders SP, Lang P, Jonas RA, Castaneda AR. Hemodynamic results of arterial switch operation for transposition of the great arteries, intact ventricular septum. Circulation 1984;70(suppl II):II-26. 4. Lange PE, Sievers HH, Omnasch DGW, Yacoub MH, Bernhard A, Heintzen $\mathrm{PH}$. Up to 7 years of follow-up after two stage anatomic correction of simple transposition of the great arteries. Circulation 1986,74(suppl I):I-47-I-52. 5. Brawn WJ, Mee RBB. Early results for anatomic correction of transposition of the great arteries and for double-outlet right ventricle with subpulmonary ventricular septal defect. $J$ Thorac Cardiovasc Surg 1988,95:230-238.

6. Gibbs JL, Qureshi SA, Grieve L, Webb C, Radley Smith R, Yacoub MH Doppler echocardiography after anatomical correction of transposition of the great arteries. Br Heart $J$ 1986;56:67-72.

7. Sidi D, Planche C, Kachaner J, Bruniaux J, Villain E, LeBidois J, Piechand J$F$, Lacour-Gayet $F$. Anatomic correction of simple transposition of the great arteries in 50 neonates. Circulation 1987,75:429-435.

8. Idriss FS, Ilbawi MN, DeLeon SY, Duffy CE, Muster AJ, Backer CL, Berry TE, Paul MH. Transposition of the great arteries with intact ventricular septum. Arterial switch in the first month of life. $J$ Thorac Cardiovasc Surg 1988,95:255262.

9. Ilbawi MN, Idriss FS, DeLeon SY, Muster AJ, Gidding SS, Duffy CE, Paul $\mathrm{MH}$. Preparation of the left ventricle for anatomic correction in patients with simple transposition of the great arteries. Surgical guidelines. $J$ Thorac Cardiovasc Surg 1987,94:87-94.

10. Lecompte $\mathrm{Y}$, Zannini L, Hazan E. Anatomic correction of transposition of the great arteries. $J$ Thorac Cardiovasc Surg 1981;82:629-631.

11. Bove EL, Beekman RH, Snider AR, Rocchini A, Dick M, Crowley DC Scrwer GA, Rosenthal A. Artcrial repair for transposition of the great arteries and large ventricular septal defect in early infancy. Circulation 1988,78(suppl III):III-26-III-3I

12. Gutgesell HP. Echncardingraphic assessment of cardiac function in infants and children. JACC 1985;5:95S-103S

13. Colan SD, Borow KM, Neumann A. Left ventricular end-systolic wall stressvelocity of fiber shortening relation: a load-independent index of myocardial contractility. JACC 1984;4:715-724.

14. Hatle L, Angelsen B. Doppler Ultrasound in Cardiology. Physical Principles and Clinical Applications. Philadelphia: Lea and Febiger, 1985:24.

15. Borow KM, Arensman FW, Webb C, Radley-Smith R, Yacoub MH. Assessment of left ventricular contractile state after anatomic correction of transposition of the great arteries. Circulation 1984,69:106-112.

16. Arcnsman FW, Radley-Smith R, Grieve L, Gibson DG, Yacoub MH. Com puter assisted echocardiographic assessment of left ventricular function before and after anatomic correction of transposition of the great arteries. $\mathrm{Br}$ Heart $J$ $1986: 55: 162-167$ 